\title{
O PENSAMENTO CONSERVADOR E SUA RELAÇÃO COM PRÁTICAS DISCRIMINATÓRIAS NA EDUCAÇÃO: A importância da laicidade
}

José Antonio Sepulveda ${ }^{(*)}$ Denize Sepulveda

A crescente presença do discurso conservador em nossa atual sociedade e a sua relação com as práticas discriminatórias estruturam a base de argumentação deste texto. Sendo assim, o objetivo principal deste artigo é demonstrar que o pensamento conservador presente na escola funciona como um agente de exclusão social com impactos graves na formação das identidades de todxs ${ }^{1}$ xs estudantxs. Um dos elementos fundamentais à compreensão de tal processo de exclusão é a forte presença da religião na escola, que atinge especificamente o princípio da laicidade do Estado.

Este trabalho encontra-se dividido em duas partes: uma que discute o conceito de conservadorismo e o relaciona com a sociedade brasileira contemporânea, outra que relaciona o conservadorismo com as práticas discriminatórias, explicitando a importância da garantia da laicidade no interior das escolas públicas brasileiras.

\section{CONSERVADORISMO}

A primeira questão que emerge ao apresentar o tema é: existe um conceito de conservadorismo? A dificuldade dessa resposta é tão grande que, segundo Bonazzi (2000), é mais fácil entender o conceito de conservador pela variedade de significados atribuídos ao adjetivo, do

\footnotetext{
(*) José Antonio Sepulveda. Professor Adjunto da Faculdade de Educação na Universidade Federal Fluminense (UFF) - Departamento de Fundamentos Pedagógicos. Doutorado em Educação pela Universidade Federal do Rio de Janeiro (UFRJ). Líder do Grupo de Estudos e Pesquisa: Conservadorismo e Educação Brasileira da UFF. E-mail: jamsepulveda3@hotmail.com.

Denize Sepulveda. Professora Adjunta da Faculdade de Formação de Professores na Universidade do Estado do Rio de Janeiro (UERJ) - Departamento de Educação. Pós-doutora em Educação pelo PROPED. Vice-Líder do Grupo de Estudos e Pesquisa "Conservadorismo e Educação Brasileira" da UFF. Coordenadora do Grupo de Pesquisa "Gênero, Sexualidades e Diversidades nos Vários EspaçosTempos Cotidianos” (GESDI) da FFP/UERJ. E-mail: denizesepulveda@hotmail.com.

${ }^{1} \mathrm{O}$ uso do "X" nas palavras, do ponto de vista linguístico e gramatical, é uma forma de usar uma linguagem escrita que expresse maior igualdade entre homens e mulheres. A língua portuguesa determina que o plural dos substantivos deva usar o gênero no masculino. Essa generalização do plural é considerada sexista e machista por certos grupos e indivíduos, resultando assim em propostas por um gênero plural não sexista a ser adotado em Português. O uso do "X" é uma tentativa de, no âmbito da escrita, tornar a língua mais democrática.
} 
que entender o substantivo conservadorismo pela dificuldade de determinar a sua natureza e os seus fins. A inexistência de uma teoria política comum que defina os conservadores e a dificuldade dos conservadores em sistematizar suas próprias ideias complica mais ainda a compreensão do termo. Com isso, o uso da palavra entra no cotidiano com sentidos variados, ganhando vida e sendo apropriado, muitas vezes, como forma de xingamento.

Outro agente complicador do termo é o seu uso relacionado ao comportamento humano. Assim, uma pessoa pode ser politicamente inovadora e ter condutas conservadoras com relação à família, ou até mesmo em relação a práticas sexuais. A primeira conclusão que podemos chegar com relação ao tema é que ele é realmente confuso e entorpecido por uma carga emotiva muito grande, uma vez que ele se relaciona também com o comportamento humano.

Se, pois, a Ciência Política realça no Conservadorismo o caráter universal, fazendo dele uma constante necessária da política, perde de vista a especificidade do termo. Trata-se, com efeito, de um resultado intencional, porquanto é preocupação comum aos psicólogos, sociólogos e politólogos evitar a forte carga emotiva a ele ligada, onde se vê, não sem razão, a causa primeira de sua ambiguidade, se não verdadeiramente o elemento que, reunindo os vários significados com que o termo é usado, lhe dá uma vida unitária fictícia. (BONAZZI, 2000, p. 242-243).

Dessa forma, a existência dessa carga emotiva é de grande importância, pois demonstra a polaridade de argumentos impregnada na sociedade contemporânea, de modo que, esta polaridade, apresenta na intensa relação existente entre o uso comum do termo conservadorismo e o uso de outro termo, inclusive ambíguo, que teoricamente representa seu antônimo, "progressismo". Em princípio, esse termo significa uma atitude otimista quanto às possibilidades de desenvolvimento humano. Assim, no senso comum, o conservadorismo se apresenta como a negação de tais possibilidades. Essa forma de compreensão reduz as práticas conservadoras à existência de práticas progressistas. Ou seja, só seria possível entender o conservadorismo a partir das práticas opostas, criando-se, assim, um caráter reativo ao termo em destaque.

A tese reativa nos parece frágil. Não acreditamos ser possível entender o conservadorismo como simples reação. Muito menos que não produza conhecimento e nem agentes políticos. Há séculos estão presentes no campo político os partidos conservadores, com propostas e agendas políticas bem desenvolvidas. Observa-se em relação a esses uma postura de proatividade, principalmente no que tange ao desenvolvimento econômico e tecnológico. Hirschman (1992) afirma que a nossa linguagem moderna está sob a influência da crença no progresso: “ela implica que o mero desenrolar do tempo traz consigo o melhoramento dos homens, de modo que qualquer volta atrás seria calamitosa" (p. 17). A denúncia feita por esse autor é correta no nosso ponto de 
vista. O fato de existirem mudanças sociais com argumentos progressistas, não necessariamente trazem benefícios para a humanidade. Exemplo disso são as propostas de reformas trabalhistas e previdenciárias que assolam o mundo hoje. Com certeza, elas significam perdas para os trabalhadores. No entanto, reagir a isso não é uma atitude calamitosa, ou seja, o dito "progresso" nem sempre é positivo.

Com efeito, é possível, no entanto, afirmar que para se entender o conservadorismo, primeiramente é necessário entendê-lo dentro do campo de debate da política. Assim, deixamos de lado a discussão do comportamento humano e nos colocamos no lugar de onde é plausível visualizar melhor o conservadorismo. Dessa forma, segundo Hirschman (1992), é admissível identificar uma retórica do conservadorismo político, a qual se apresenta como enfrentamento a qualquer mudança de ordem política que se proponha, de alguma forma, a modificar as relações de poder estabelecidas em uma sociedade. Neste sentido, o conservadorismo político é inaugurado por Edmund Burke em sua crítica à Revolução Francesa. O principal medo desse autor era a modificação nas relações sociais, principalmente, a ascensão de novas classes sociais ao poder.

O conservadorismo surge como resposta necessária às teorias que, a partir do século XVIII, se distanciaram da visão antropológica tradicional, para reivindicar para o homem a possibilidade, não só de melhorar o próprio conhecimento e seu domínio sobre a natureza, como também de alcançar, por meio de ambos, uma autocompreensão cada vez maior e, consequentemente, a felicidade. O resultado a que tendiam estas teorias era o de fazer da história humana um processo aberto e ascendente, baseado numa antropologia revolucionária, onde o indivíduo fosse núcleo ativo, capaz de se tornar melhor tornando-se cada vez mais racional. (BONAZZI, 2000, p. 243)

Dessa forma, a possibilidade de mudança produzia um efeito de cisão na tradicional e estática concepção de mundo que vinha da idade média. A visão cristã, oficial no mundo ocidental, entendia as relações humanas, e consequentemente a política, como uma espécie de providência divina. Muitos autores como De Maistre e De Bonaldi, defendiam que qualquer tentativa de mudança social e política seria inútil e que acarretaria em uma espécie de vingança divina, que levaria todas as mudanças a retornar a um ordenamento religioso. (HIRSCHMAN, 1992).

A partir da constatação acima, Hirschman (1992) passa a identificar três teses recorrentes da retórica conservadora: tese da perversidade, tese da futilidade e tese da ameaça.

De acordo com a tese da perversidade, qualquer ação proposital para melhorar um aspecto da ordem econômica, social ou política só serve para exacerbar a situação que se deseja remediar. A tese da futilidade sustenta que as tentativas de transformação social serão infrutíferas, que simplesmente não conseguirão 'deixar uma marca'. Finalmente, a tese da ameaça argumenta 
que o custo da reforma ou mudança proposta é alto demais, pois coloca em perigo outra preciosa realização anterior. (p. 15).

É obvio que tais argumentos não são invocados somente por conservadorxs, qualquer grupo pode e faz uso deles, principalmente quando os partidos conservadores estão no poder. O problema é o momento e os objetivos pelos quais as teses são utilizadas. Quando essas são empregadas para evitar qualquer transformação na ordem social ou melhorias reais para as classes trabalhadoras, ou para qualquer grupo minoritário, temos uma retórica conservadora. Vale destacar que quando xs conservadorxs do campo político têm que discutir qualquer assunto de natureza moral ou comportamental, elxs tendem a defender os valores tradicionais. Como já mencionado acima, quando tratamos de comportamento humano, o termo conservadorismo se torna mais complexo. Assim, para facilitar a análise, quando do debate desses assuntos no campo político, xs conservadorxs estão sempre contrários às minorias. Temas como direitos sexuais e reprodutivos e descriminalização das drogas estão sucessivamente na mira dxs conservadorxs por simbolizarem um afastamento do ordenamento religioso do comportamento social.

Dessa forma, retornamos ao problema do comportamento humano. Afinal, pessoas de diferentes partidos políticos, inclusive não conservadoras, podem adotar visões conservadoras em relação a alguns temas. Todavia, o fato de ter visão conservadora não necessariamente implica em conservadorismo político. Por exemplo, uma pessoa pode ser contra o aborto e apoiar a descriminalização do aborto. Nesse caso, ela enquanto indivíduo não pratica o aborto, mas também não criminaliza quem pratica, se posicionando assim de forma contrária ao conservadorismo político. Assim, só é possível se tratar do comportamento humano quando esse está no campo político, fora desse campo todas as atitudes são de foro íntimo, por isso, não passível de qualquer análise política.

Uma vez entendido que o conservadorismo político contemporâneo se originou a partir da crítica ao Iluminismo e à Revolução Francesa, entendemos que os marcos classificatórios do conservadorismo estão nas propostas de transformação social que aumentam a participação e os direitos das camadas mais pobres da sociedade. Dessa forma, o conservadorismo político é contrarrevolucionário e antidemocrático. Hirschman (1992), citando Marshall (1949), aponta três momentos em que o discurso conservador esteve mais ativo: na luta contra os direitos civis defendidos pela Revolução Francesa, depois na luta contra os direitos políticos, em especial no século XIX contra o sufrágio universal, e, por fim, na luta contra o Estado Social, o "welfare state", no embate contra as políticas sociais e de assistência. Sendo assim, ele não define o que é o 
conservadorismo, ele simplesmente identifica a retórica conservadora, ou seja, nossa questão inicial continua.

A tentativa de Hirschman (1992) de construir um conjunto de teses que determinam uma retórica reacionária acaba reduzindo as possibilidades de interpretação da dinâmica conservadora. As próprias mudanças sociais, inclusive as utilizadas por Hirschman citando Marshall, demonstram um processo de adequação do discurso reacionário, fruto de disputas internas dentro do próprio campo conservador, o que não é devidamente trabalhado pelo autor. Tal limitação em seu trabalho é fruto de uma opção teórico-metodológica que não leva em conta a diversidade e a complexidade das relações humanas, principalmente por não visibilizar a dinâmica das relações de classe social.

Nesta análise que propomos, o conservadorismo é uma categoria histórica, ou seja, deriva de processos sociais através do tempo. Conhecemos o conservadorismo porque frequentemente as pessoas se comportam de forma conservadora. Este processo histórico gera certa regularidade de argumentos para situações análogas, o que nos permite observar o desenvolvimento de uma cultura conservadora. Dessa forma, não é possível se pensar em conservadorismo como uma categoria estática, tanto sociológica quanto antropologicamente.

Com efeito, o conteúdo do conservadorismo só se pode explicar com base na história, todavia, não se pode dizer como afirma Bobbio (1992), Bonazzi (1992) e outros autores, que o conservadorismo não é uma teoria e não é teorizante. Pelo contrário, todas as teorias podem ser conservadoras e endossarem o conservadorismo na sociedade, afinal o termo se refere a um conjunto de práticas e de retóricas que inviabilizam e dificultam a mobilidade social. Ou seja, a história é marcada por disputas, em especial por aquilo que se vinculou chamar de "luta de classes". O conservadorismo é um elemento ideológico que constrói senso comum. Portanto, não é exclusivo de nenhuma classe social. Na disputa por poder que ocorre no campo da cultura o conservadorismo é um importante elemento na construção dos interesses de classe e na própria consciência de classe. Em tal processo, não estão em disputa somente as condições materiais de sobrevivência, estão também as condições simbólicas, compostas por diversas argumentações de diferentes naturezas. O que torna o processo de conscientização mais lento.

Classe e consciência de classe são sempre o último e não o primeiro degrau de um processo histórico real. Mas se adotarmos uma concepção estática da categoria de classe, ou se fizermos descender esse nosso conceito de um modelo teórico preliminar de totalidade estrutural, não procederemos assim, pois estaremos subentendendo que a classe está presente desde o início como um resultado de relações de produção. (THOMPSON, 2012, p. 274). 
Ao afirmarmos que classe e consciência de classe são sempre a última fase de um processo real, naturalmente não pensamos que isso seja tomado no sentido literal e mecânico. Uma vez que se tem uma consciência de classe desenvolvida, os jovens podem ser "socializados" em um sentido classista, e as instituições de classe prolongam as condições para sua formação. Podem-se gerar tradições ou costumes de antagonismos de classe que não correspondam mais a um antagonismo de interesses. Mas tudo isso faz parte da complexidade que habitualmente encontramos na nossa análise histórica, especialmente a contemporânea. A questão é que não podemos falar de classes sem que as pessoas, diante de outros grupos, por meio de um processo de luta (o que compreende uma luta em nível cultural), entrem em relação e em oposição sob uma forma classista, ou ainda sem que modifiquem as relações de classe herdadas, já existentes (THOMPSON, 2012).

A compreensão do Thompson (2012) em romper com a tradição marxista ortodoxa, que coloca em oposição a base e a superestrutura, é fundamental para o argumento que defendo neste trabalho. Não é possível entender o conservadorismo desvinculado dos interesses de classe, mas não é só isso. O conservadorismo é reproduzido como argumento de uma retórica que ultrapassa as questões de classe, encontrando as questões abstratas de sobrevivência que estão em disputa no campo da cultura, em especial nas diferentes demandas dos grupos minoritários: mulheres, lésbicas, homossexuais, negrxs, etc. Isso não quer dizer que a luta de classes desapareça. Ela simplesmente se torna mais complexa com mais variantes ocorrendo em diferentes espaços sociais.

Essas disputas se dão em todos os campos sociais e é objeto de interesse especial para o campo da educação, uma vez que as demandas dos diferentes grupos estão encontrando respaldo no campo político, exigindo uma política educacional adequada as suas conquistas. Um exemplo disso é a lei 10.639/2003, que altera a Lei de Diretrizes e Bases de 1996, tornando obrigatório o ensino de história da África e cultura afro-brasileira. Nesse caso, as disputas do campo político se materializaram de forma objetiva em uma lei, que não resolve o problema, já que a maioria das escolas ainda não a cumpriu, mas cria condições objetivas de luta. Todavia, muitas demandas ainda estão em fase preliminares de disputa. Esse é o caso da comunidade LGBTIs, que recentemente vem sofrendo reveses dos conservadores políticos, principalmente daqueles oriundos das bancadas religiosas dentro das Assembleias legislativas do Brasil. Avanços e retrocessos ainda marcam a sua história. Nesse contexto, muitxs jovens lésbicas, homossexuais ou aquelxs que apresentam um comportamento de gênero diferente a norma padrão vêm sofrendo maus tratos em algumas escolas. São vários os casos de lesbofobia e homofobia ocorridos nas escolas brasileiras que vêm influenciando nas tessituras identitárias de todxs xs estudantes. 
Nesse cenário, as práticas impetradas às lésbicas e aos homossexuais estão fundamentadas no pensamento conservador político, fruto de um discurso hegemônico que preconiza a heterossexualidade como a norma metro-padrão do comportamento sexual. Nesse discurso está fomentando a construção do preconceito contra essas pessoas, tornando-se, assim, um instrumento poderoso de manutenção das hierarquias sociais, morais e políticas, e produzindo as hierarquizações que levam às construções das inferiorizações e dos preconceitos, tão presentes nos cotidianos de nossas escolas, levando muitas alunas e alunos a viverem violentos processos de exclusão escolar e social a partir de situações de subalternidade por parte de algumas professoras e professores religiosxs.

Vale ressaltar também que são utilizadas pelxs políticxs conservadorxs, em grande escala, a tese da ameaça apontada por Hirschman (1992), principalmente com relação às questões de gênero. $\mathrm{Na}$ prática, o conservadorismo político trabalha com a tese de que as homossexualidades vão destruir a família, disseminando o medo na sociedade, de modo que a escola deve se defender de tal ameaça.

Há de se considerar que este discurso é muito bem elaborado, pois em alguns casos, sua construção está revestida de ideias progressistas. Vejamos o caso do que hoje está sendo chamado de "ideologia de gênero". Esse termo foi desenvolvido pelo pensamento político conservador para designar uma pretensa prática escolar de ensinar que a criança pode ter e desenvolver qualquer identidade de gênero, independente de sua identidade sexual. Ou seja, o que xs conservadorxs políticxs dizem é que a escola está ensinando xs alunxs a serem lésbicas e homossexuais.

Alguns discursos contrários a tal "ideologia de gênero" defendem a ideia de que existe, por trás dessa proposta, uma tese para destruir os avanços recentes na organização das famílias. Citamos como exemplo, o divórcio, que proporcionou uma ruptura com a família nucleada, gerando famílias estendidas. Posteriormente, as modificações nas configurações familiares possibilitaram o reconhecimento de casamentos lesboafetivos e homofetivos. Essas são transformações importantes que estão sendo colocadas em risco pelo discurso político conservador. Nesse sentido, xs conservadorxs políticxs argumentam que a "ideologia de gênero" pode colocar em risco as conquistas progressistas recentes conseguidas na estrutura social.

(...) se for possível demonstrar que duas reformas são de algum modo mutuamente excludentes, de maneira que a mais antiga é posta em perigo pela mais recente, introduzir-se-á no argumento um novo elemento de comparabilidade, e a avaliação pode prosseguir em termos de 'moedas de progresso' vagamente comuns: tem sentido sacrificar o progresso antigo pelo novo? Além disso, com esse tipo de argumentação, o reacionário veste-se com a roupagem progressista (...). (HIRSCHMAN, 1992, p. 75). 
Uma coisa é aceitar a homossexualidade outra coisa é ensinar as crianças a serem homossexuais. Por conta desses argumentos, há uma campanha conservadora nacional contra a inclusão da discussão de gênero nas escolas, contra uma pretensa homossexualização da sociedade. A campanha propaga o medo, o fim das famílias, tanto as nucleadas como as estendidas, e a depravação social. É preciso manter vivo o espírito religioso dentro da escola a fim de evitar a ideologia de gênero.

Entramos agora no ponto mais complexo da análise. Como defender a família e o discurso religioso nas escolas públicas em um Estado laico com uma "escola laica"?

Nossas alunas e alunos frequentam a escola durante pelo menos doze anos, entre o Ensino Fundamental e o Ensino Médio, ficam em torno de quatro a quatro horas e meia por dia na instituição escolar, durante nove meses e meio, perfazendo um total de duzentos dias letivos por ano. Durante todo esse tempo aprendem como devem se comportar a partir das hierarquizações e inferiorizações que vão sendo travadas nos cotidianos das escolas. A partir da retórica e de práticas conservadoras de algunxs professorxs religiosxs que são desenvolvidas em nossas instituições educacionais, não há como não tecerem uma aprendizagem sobre o que é considerado correto. Através da retórica e do pensamento conservador, os dispositivos de poder se inter-relacionam e se estabelecem no interior das instituições educacionais, evidenciando assim que as maneiras de produzir verdade se materializam em práticas políticas que interferem nos modos como se tecem a vida e a prática profissional. Assim, todxs xs alunxs vão percebendo que existe uma conduta considerada como "normal". A retórica conservadora é intransigente (HIRSCHMAN, 1992) e faz uso dos mais diferentes discursos. Um desses é o religioso. Tal discurso é extremamente poderoso e com efeitos variados. O discurso religioso é muito comum nas escolas brasileiras (historicamente organizada pelo campo religioso) e acaba afetando todxs xs estudantes. Portanto, não é necessário defender o discurso religioso na escola. Ele faz parte da escola. Assim, se o discurso religioso é conservador e ele faz parte da escola, por que os conservadores temem tanto a ideologia de gênero? Se o discurso religioso é um dos argumentos utilizados pelos defensores do fim da "ideologia de gênero", por que o medo de tal discurso na escola?

A reposta para isso só é possível se pensarmos na dinâmica constante da luta de classes. Mais uma vez, nos baseando em Thompson (2012), entendemos que o processo objetivo por construção de relações de classe depende, principalmente para xs conservadorxs, de um intenso trabalho de convencimento de classe. O que deve ser objeto de preocupação para elxs é a reprodução das relações existentes, mesmo que adaptadas historicamente ao período. Dessa forma, 
os espaços institucionais, como a escola, são extremamente importantes para se manter e reproduziras desigualdades sociais.

Essa questão fica mais óbvia se pegarmos o movimento conservador mais ativo hoje no Brasil: o projeto Escola sem Partido. Desde 2014, período da discussão e aprovação do atual Plano Nacional de Educação, o movimento Escola sem Partido vem propondo projetos de lei que estão sendo apresentados nos estados e municípios com nomes variados, mas com os mesmos objetivos, tendo como referência o PL 2731/2015 proposto pelo deputado Eros Biondini (PTB-MG), que, "Altera a Lei 13.005, de 25 de junho de 2014, que estabelece o Plano Nacional de Educação - PNE e dá outras providências". Este novo projeto de lei altera o Plano Nacional de Educação para "dispor sobre a proibição do uso da ideologia de gênero na educação nacional". Este projeto vem tramitando apensado com outros, inclusive o 867/2015, que estabelece o Programa Escola Sem Partido. Tal programa afirma que o governo esquerdista do Partido dos Trabalhadores (PT), por ser marxista cultural, defende que a educação brasileira é muito influenciada pelo marxismo do educador Paulo Freire, que quer destruir os valores simples e humildes da população brasileira, incitando à revolução. O projeto Escola sem Partido foi criado pelo advogado e procurador do Estado de São Paulo Miguel Nagib, que denuncia que os professores nas escolas são doutrinadores de esquerda, mais especificamente, aliciadores do Partido dos Trabalhadores.

\section{O COMPLEXO PROBLEMA DA LAICIDADE NA ESCOLA PÚBLICA}

No contexto de disputa de interesses pelo controle da escola pública no Brasil, a retórica religiosa, como já foi mencionada acima, é extremamente importante. Todavia, o Estado Moderno se constituiu a partir de um processo de laicização, ou seja, em um movimento de afastamento das posições religiosas, o qual define que a religião não poderia dominar a esfera pública, caracterizando as diferenças efetivas entre o que era público, defendido pelo Estado laico, e o que era privado. Nesse contexto, as religiões passaram a ser entendidas como um direito individual, não cabendo, dessa forma, ao Estado criar nenhum tipo de relação com nenhuma religião a fim de respeitar as diferentes manifestações religiosas da população.

O Estado se tornou laico, vale dizer tornou-se equidistante dos cultos religiosos em assumir um deles como religião oficial. A modernidade vai se distanciando cada vez mais do cujus regio, ejus religio. A laicidade, ao condizer com a liberdade de expressão, de consciência e de culto, não pode conviver com um Estado portador de uma confissão. Por outro lado, o Estado laico não adota a religião da irreligião ou da antirreligiosidade. Ao respeitar todos os cultos e não adotar nenhum, o Estado libera as igrejas de um controle no que toca à especificidade do religioso e se libera do controle religioso. Isso quer dizer, ao mesmo tempo, o deslocamento do 
religioso do estatal para o privado e a assunção da laicidade como um conceito referido ao poder de Estado. (CURY, 2004, p. 183).

A laicização do Estado foi proclamada para retirar o monopólio da verdade da Igreja no processo de construção moderna da sociedade democrática. A laicidade é um princípio da construção da democracia.

Todavia, as instituições religiosas, especialmente a Igreja Católica, jamais aceitou tal laicização, e, no próprio desenvolvimento da democracia, passou a exigir mais participação política. Afinal, tal instituição representava os interesses de milhões de pessoas no planeta. O Estado Moderno, então, passou a conviver com momentos de crescimento religioso da sociedade e do Estado. Isso não foi diferente no Brasil, pelo contrário, possivelmente, foi mais intenso aqui do que na maioria dos outros países, pelo menos do mundo ocidental.

As instituições religiosas no Brasil, principalmente a Igreja Católica, apostaram na disputa pelo controle do Estado e da população a partir do controle de algumas instituições sociais. Controlar essas instituições se tornou uma importante arma contra a secularização da sociedade. $\mathrm{O}$ que tais instituições entenderam? O perigo que era a perda de fieis, pois isso poderia significar a diminuição de seu grau de influência social e política no país.

Nesse contexto, a disciplina escolar ensino religioso se tornou fundamental para impedir qualquer avanço da secularização da sociedade brasileira e recuperar a influência política perdida, principalmente a partir da proclamação da República no Brasil.

Na década de 1930, o ensino religioso retornou às escolas públicas com determinação constitucional (CUNHA, 2013). Ou seja, desde a constituição de 1934, a primeira a enfatizar a obrigatoriedade do ensino religioso, a disputa entre laicos e religiosos pelo controle da escola pública se intensificou no Brasil.

Como já mencionado acima, o ensino religioso não era a única forma pelo qual a religião esteve presente na escola. A presença da religião na maioria das escolas públicas brasileiras, em seus vários contextos e diversas formas, sinaliza a já mencionada ambiguidade entre o público e o privado. Tal equívoco é decorrente de articulações e do embate de forças entre diferentes grupos políticos.

Segundo Fernandes (2014), através de articulações políticas o ER tem assegurado consecutivas conquistas nos documentos legais, através de artigos que acolhem seus interesses materiais e simbólicos em detrimento das "conquistas republicanas do Estado laico e da liberdade 
religiosa" (GIUMBELLI; CARNEIRO, 2004), expandindo cada vez mais a privatização do espaço público.

Assim, podemos inferir que a presença compulsória do ensino religioso no currículo das escolas públicas brasileiras, ou da religião, expressa a partir das práticas de alguns profissionais, que Estado e Igreja, de acordo com a história, se robustecem reciprocamente, suscitando tensões e conflitos e enfraquecem o princípio da laicidade do Estado.

Ainda de acordo com Fernandes (2014), as tensões e conflitos prosseguem provocando discussões e disputas, isso porque a maioria do ensino religioso desenvolvido nos cotidianos das escolas se dá a partir dos preceitos cristãos em prejuízo da pluralidade religiosa presente no contexto brasileiro.

Depois de ser, durante séculos, lugar de dominação católica, as escolas públicas brasileiras passaram a ser lugar de disputa entre crenças e seus respectivos cleros: padres, pastores, bispos e agentes leigos protagonizam uma disputa pela hegemonia, oculta ou aberta. Nessa luta, os perdedores permanecem os mesmos: os adeptos do espiritismo, das religiões afro-brasileiras e de credo minoritários. E os não religiosos, que são alvos de todo o tipo de estigmas. (...) (CUNHA, 2013, p. 7).

Assim, em nome da liberdade religiosa, a laicidade do Estado deve ser garantida de forma que "todos possam conviver sem ter que manifestar essa dimensão da vida, fazendo-o apenas se quiser" (FISCHMANN, 2008, p. 13).

Um Estado laico não se associa com nenhuma religião e também não presta privilégio. Portanto, não a financia com recursos públicos e nem estabelece convênios de qualquer ordem, pois tem a obrigação de assegurar a liberdade religiosa para todos os sujeitos.

Laico é o Estado imparcial diante das disputas do campo religioso, que se priva de interferir nele, seja pelo apoio, seja pelo bloqueio a alguma confissão religiosa. Em contrapartida, o poder estatal não é empregado pelas instituições religiosas para o exercício de suas atividades. (CUNHA, 2013, p. 7).

Destaca-se, contudo, que o ensino religioso não se manifesta apenas na sala de aula com professorxs dedicado a essa tarefa. Esta é apenas uma das formas de ocupação desse espaço público, amplamente disputado pelas religiões. Há outras maneiras de ensinar religião e ocupar a escola, ainda que não sustentadas por instrumentos legais como a disciplina em questão. A exposição de símbolos religiosos nas salas de diretores, no pátio, a prática de orações realizadas em determinadas situações, missas, bíblias expostas e tantas outras manifestações que privilegiam crenças, também são formas de ensinar e colonizar o ambiente escolar. São as relações 
patrimonialistas que ainda persistem nas relações sociopolíticas do país, na qual o agente público faz uso do patrimônio do Estado como se fosse seu bem particular, o que torna difuso o limite entre o público e o privado. Entender essa realidade permite extrair reflexões teóricas e, ao mesmo tempo, embasar ações práticas que busquem garantir o respeito às diferenças e à liberdade de crença, normalmente comprometidos com a presença do ensino religioso no ambiente reservado à educação.

Todavia, a laicidade ultimamente vem sendo usada como retórica de argumentação dxs conservadorxs. O movimento Escola sem Partido tem afirmado que o princípio da laicidade está sendo ameaçado (a tese da ameaça do Hirschman), uma vez que a escola vem sofrendo um processo de ideologização esquerdista. Professorxs vem ensinando, segundo elxs, suas visões particulares de mundo, de forma praticamente religiosa. E como agentes públicos não podem fazer proselitismo de nenhuma forma em instituições públicas de ensino, ferindo assim o artigo 33 da LDBEN, referente ao ensino religioso, que veda todas as formas de proselitismo religioso dxs professrxs. Se xs professorxs não podem ensinar as religiões que acreditam, elxs também não podem ensinar as suas visões políticas esquerdistas. Segundo xs conservadorxs, a esquerdização, assim como a já mencionada ideologia de gênero, fere o princípio da laicidade do Estado.

Não se pode negar a eficiência de tal discurso, apesar de extremamente incoerente. Afinal, proibir práticas de aulas com debates políticos, não impedem a existência do debate político. Assim como a laicidade não impede a presença da religião na escola. Nem é isso que preconiza a defesa da escola laica. A laicidade não é ateísmo ou agnosticismo. É o reconhecimento que o espaço público da escola pública não é lugar para se defender nenhuma religião, assim como não é o local para que se faça nenhuma doutrinação política. Todavia, a política e a religião são importantes conteúdos que devem ser debatidos na escola, inclusive de forma transdisciplinar, científica e crítica. 


\section{REFERÊNCIAS}

BONAZZI, Tiziano. Verbete conservadorismo. In: BOBBIO, N.; MATTEUCCI, N.; PASQUINO, G. Dicionário de política. Brasília: Editora UnB; São Paulo: Imprensa Oficial do Estado de São Paulo, 2000.

BORRILO, Daniel. Homofobia: história e crítica de um preconceito. Belo Horizonte: Autentica, 2010.

BRASIL. Constituição (1988). Constituição da República Federativa do Brasil. Diário Oficial da União. Brasília: Congresso Nacional, 05 out. 1998. Anexo. Disp.: http://www.planalto.gov.br/ccivil 03/constituicao/Constitui\%C3\% A7ao91.htm. Acesso em: 10 abr. 2016.

. Lei 10.639, de 09 de janeiro de 2003. Altera a Lei de Diretrizes e Bases da Educação Nacional 9.394/96 para incluir no currículo oficial da Rede de Ensino a obrigatoriedade da temática "História e Cultura Afro-Brasileira". Diário Oficial da União. Poder Legislativo, Brasília, 10 jan. 2003, p. 1. Disp.; <http://www.planalto.gov.br>. Acesso em: 10 de abr. 2016.

Projeto de Lei 2.731/2015. Altera a Lei 13.005, de 25 de junho de 2014, que estabelece o Plano Nacional de Educação - PNE e dá outras providências". Disp.: http://www.planalto.gov.br>. Acesso em: 10 de abr. 2016.

. Projeto de Lei 867/2015. Estabelece o Programa Escola Sem Partido. Disp.: 〈http://www.planalto.gov.br>. Acesso em: 10 de abr. 2016.

CUNHA, Luiz Antônio. Sintonia oscilante: religião, moral e civismo no Brasil - 1931/1937. Cadernos de Pesquisa, v. 37, n. 131, p. 285-302, maio/ago. 2007.

. Ambiguidade Ideológica na Universidade: os Estudos de Problemas Brasileiros. Revista do CFCH, Rio de Janeiro:, UFRJ, 2010.

. Educação e Religiões: A descolonização religiosa da Escola Pública. Belo Horizonte: Mazza Editora, 2013.

CURY, Carlos Roberto Jamil. Ensino religioso na escola pública: o retorno de uma polêmica recorrente. Revista Brasileira de Educação, [s.l.: s.n.], n. 27, set./dez. 2004.

ESQUIVEL, Juan Cruz. A Igreja Católica e o Estado na Argentina e no Brasil. Notas introdutórias para uma análise comparativa. Revista Ciências Sociais e Religião, Porto Alegre, ano 5, n. 5, 2003.

FERNANDES, Vânia Claudia. (As)Simetria nos Sistemas Públicos de Ensino Fundamental em Duque de Caxias (RJ): a religião no currículo. Tese (Doutorado em Educação) - Pós-Graduação em Educação, Universidade Federal do Rio de Janeiro, Rio de Janeiro, 2014.

FERRARI, Anderson. Você já deve saber sobre minha "orientação sexual" (se não sabia, ficou sabendo agora, hehe) subjetividades e sujeitos em negociação. In: FERRARI, Anderson. Sujeitos, subjetividades e Educação. Juiz de Fora: UFJF, 2010.

FISCHMANN, Roseli. Estado laico. São Paulo: Fundação Memorial da América Latina, 2008.

GUIUMBELli, Emerson; CARNEIRO, Sandra de Sá. Ensino Religioso no Estado do Rio de Janeiro: Registros e Controvérsias. Rio de Janeiro: Iser, 2004.

FOUCAULT, Michel. A ordem do discurso. São Paulo: Loyola, 1996.

HIRSCHMAN, Alberto. A Retórica da intransigência: perversidade, futilidade, ameaça. São Paulo: Cia das Letras, 1992.

PRADO, Marco Aurélio Máximo; MACHADO, Frederico Viana. Preconceito contra a homossexualidade: a hierarquia da invisibilidade. São Paulo: Cortez, 2008.

THOMPSON, E. P. As peculiaridades dos ingleses e outros ensaios. Campinas, SP: Editora da Unicamp, 2012. 


\section{RESUMO}

O objetivo deste texto é relacionar a retórica conservadora com as propostas e práticas discriminatórias no interior da escola. Para isso, foi feita uma reflexão teórica sobre o conceito de conservadorismo. Após, foi desenvolvida uma proposta de análise do conservadorismo a partir da concepção de luta de classes defendida por Thompson, permitindo entender como funciona a discriminação nas escolas públicas. Foi feita uma análise documental das principais leis que endossam práticas conservadoras na escola, com foco na discussão da "ideologia de gênero" e do movimento Escola sem Partido. O texto conclui afirmando a importância de um debate cuidadoso acerca da laicidade como instrumento de resistência às práticas conservadoras.

Palavras-chave: Conservadorismo. Discriminação. Laicidade.

\section{ABSTRACT}

The purpose of this paper is to relate the conservative rhetoric to the proposals and discriminatory practices within the school. For this, we made a theoretical reflection on the concept of conservatism. Made this reflection, a draft analysis of conservatism from the class struggle of design advocated by Thompson was developed, allowing understand how discrimination works in public schools. Documentary analysis of the main laws that endorse conservative practices in school, focusing on discussion of such "gender ideology" and "Escola sem Partido" movement was made. The text concludes by stating the importance of careful debate on secularism as an instrument of resistance to conservative practices.

Keywords: Conservatism. Discrimination. Secularism.

Submetido em Ago./2016

Aprovado em Dez./2016 